ARTICLE

\title{
Pressure-induced nano-crystallization of silicate garnets from glass
}

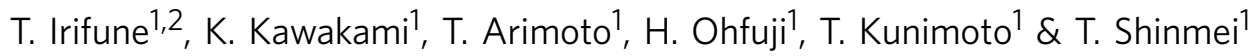

Transparent ceramics are important for scientific and industrial applications because of the superior optical and mechanical properties. It has been suggested that optical transparency and mechanical strength are substantially enhanced if transparent ceramics with nanocrystals are available. However, synthesis of the highly transparent nano-crystalline ceramics has been difficult using conventional sintering techniques at relatively low pressures. Here we show direct conversion from bulk glass starting material in mutianvil high-pressure apparatus leads to pore-free nano-polycrystalline silicate garnet at pressures above $\sim 10 \mathrm{GPa}$ in a limited temperature range around $1,400{ }^{\circ} \mathrm{C}$. The synthesized nano-polycrystalline garnet is optically as transparent as the single crystal for almost the entire visible light range and harder than the single crystal by $\sim 30 \%$. The ultrahigh-pressure conversion technique should provide novel functional ceramics having various crystal structures, including those of high-pressure phases, as well as ideal specimens for some mineral physics applications.

\footnotetext{
${ }^{1}$ Geodynamics Research Center, Ehime University, Matsuyama 790-8577, Japan. ${ }^{2}$ Earth Life Science Institute, Tokyo Institute of Technology, Tokyo 152-8550, Japan. Correspondence and requests for materials should be addressed to T.I. (email: irifune@dpc.ehime-u.ac.jp).
} 
C onventional ceramics are made of inorganic crystals, such as oxides and silicates, produced by firing raw materials in an oven, which are generally hard but fragile partly due to the presence of a large fraction of inter-crystalline pores. The presence of the pores, in addition to ionic and covalent bonding nature of these crystals, makes the ceramics good electrical and thermal insulators, which have been utilized for potteries, tiles, bricks and so on from ancient time. These ceramics are opaque even if the crystals themselves are transparent because of scattering of lights by the pores or additive materials.

Transparent ceramics have been synthesized by various methods, such as hot isostatic pressing, Spark Plasma Sintering and crystallization from glass at ambient pressure or relatively low pressures far below $10 \mathrm{GPa}$, by minimizing the lightscattering sources ${ }^{1}$. Highly transparent ceramics having transparencies close to those of the corresponding single crystals, mostly with cubic crystallographic symmetry, have been synthesized and commercialized as optical lenses, laser amplifiers and so on ${ }^{1}$. These transparent ceramics are made of crystals with grain sizes greater than a few hundred nanometres mainly due to grain growth at high temperature, while synthesis of such transparent ceramics with purely nano-crystals, having grain sizes $<100 \mathrm{~nm}$ (ref. 2), at lower temperatures have not been realized ${ }^{3-8}$ mainly because of the difficulty in removing inter-grain residual pores. However, it is predicted that the optical transparency will be significantly improved for the ceramics even with non-cubic crystals, if those made of nano-crystals are available $^{9,10}$. Moreover, the hardness of such ceramics is suggested to be also enhanced in the nano-crystalline regime ${ }^{7,11}$.

We succeeded to synthesize ultrahard nano-polycrystalline diamond (NPD) by direct conversion from graphite at high pressure and high temperature using multianvil apparatus ${ }^{12}$. Relatively large NPD rod samples up to $\sim 1 \mathrm{~cm}$ in both diameter and length can now be produced using a large-volume multianvil apparatus ${ }^{13}$, and have been successfully applied for various industrial tools as the first commercialized products obtained in the ultrahigh pressure regime (generally defined as the pressure range of above $10 \mathrm{GPa}$ in materials synthesis). By applying a similar technique, we recently reported synthesis of nanopolycrystalline stishovite ${ }^{14}$ (a high-pressure polymorph of $\mathrm{SiO}_{2}$ quartz) from silica glass with both high hardness and toughness at a pressure of $15 \mathrm{GPa}$ and temperatures above $1,000^{\circ} \mathrm{C}$. However, thus-synthesized samples exhibited only poor optical transparency.

Here we report the results of a systematic investigation of synthesis and characterization of sintered bodies of polycrystalline $\mathrm{Ca}_{3} \mathrm{Al}_{2} \mathrm{Si}_{3} \mathrm{O}_{12}$ grossular garnet at pressures to $15 \mathrm{GPa}$ and temperatures to $1,600^{\circ} \mathrm{C}$ under perfectly dry conditions and quasi-hydrostatic pressures in multianvil high-pressure apparatus. Nano-polycrystalline grossular, which is as transparent as the single crystal grossular and harder than the single crystal, is obtained at pressures above $\sim 10 \mathrm{GPa}$ at the modest temperatures around $1,400^{\circ} \mathrm{C}$. Similarly, transparent garnets with various chemical compositions are also synthesized under these pressure and temperature conditions. The successful synthesis of the super-transparent nano-polycrystalline garnet is attributed to rapid nucleation of the crystals followed by their slow grain growth under such ultrahigh pressures at the modest temperatures.

\section{Results}

Microstructure and grain size of synthesized grossular. Transmission electron microscope (TEM) and optical microscope images of the samples synthesized at $15 \mathrm{GPa}$ and at temperatures of $1,200-1,600^{\circ} \mathrm{C}$ are shown in Fig. 1 . The sample recovered from the run at $1,100{ }^{\circ} \mathrm{C}$ was colourless and transparent but remained glass. On increasing temperature, the recovered sample got devitrified to milky white at $1,200^{\circ} \mathrm{C}$ (Fig. 1a, inlet), and again became colourless and highly transparent at temperatures of $1,300,1,400$ and $1,500^{\circ} \mathrm{C}$ (Fig. $1 \mathrm{~b}-\mathrm{d}$ inlet). The sample synthesized at $1,600^{\circ} \mathrm{C}$ was also transparent but slightly dark and
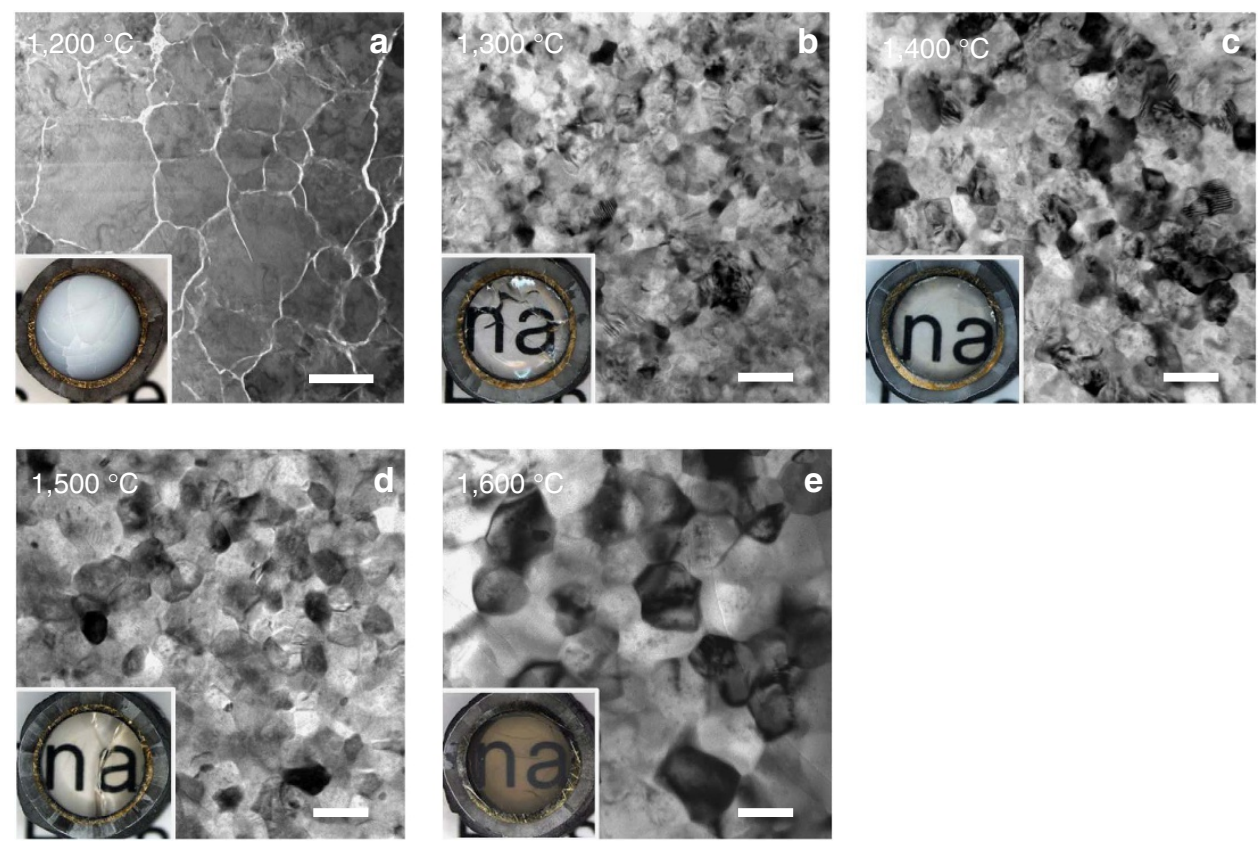

Figure 1 | TEM and optical microscope images of polycrystalline grossular samples synthesized at 15 GPa. (a) Grossular with the large grains up to a few micrometres with many inter-grain crack openings formed at $1,200^{\circ} \mathrm{C}$. (b-d) Nano-polycrystalline grossular with high optical transparency formed at temperatures $1,300-1,500^{\circ} \mathrm{C}$. (e) Grossular synthesized at $1,600^{\circ} \mathrm{C}$ was slightly dark and brown in colour with some grain growth to $\sim 200 \mathrm{~nm}$. The grossular bulk samples have diameters of $\sim 4 \mathrm{~mm}$ after the recovery, as shown by the inlet optical microscope images, where the cross-sections of surrounding metal capsule and $\mathrm{MgO}$ sleeve are also seen. The scale bar in $\mathbf{a}$ is $2 \mu \mathrm{m}$, while those in other pictures are $200 \mathrm{~nm}$. 

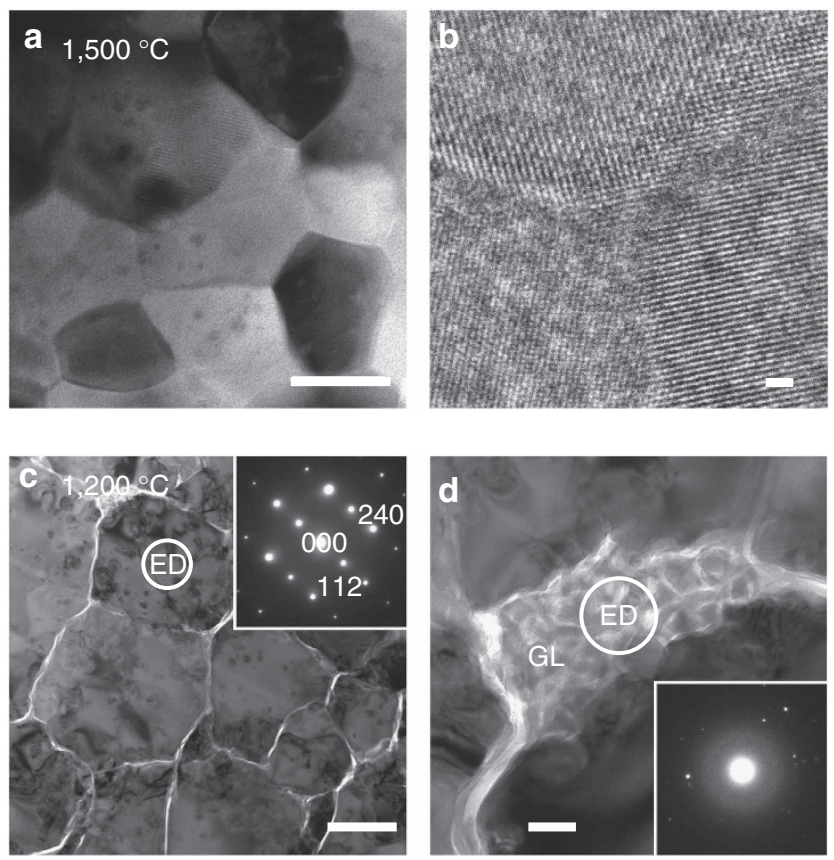

Figure 2 | Detailed TEM images of polycrystalline grossular samples synthesized at $1,500^{\circ} \mathrm{C}$ and $1,200^{\circ} \mathrm{C}$ at $15 \mathrm{GPa}$. The sample synthesized at $1,500^{\circ} \mathrm{C}$ consists of nano-crystalline grains that are tightly contacted with each other with virtually no pores or openings (a); scale bar, $100 \mathrm{~nm}$. High-resolution TEM image of a triple junction indicates that the individual grains are crystalline up to grain boundary and closely interlocked (b); scale bar, $1 \mathrm{~nm}$. The sample synthesized at $1,200^{\circ} \mathrm{C}$ consists of microcrystalline grains with a number of tangled dislocations and inter-grain micro crack openings (c); scale bar, $1 \mu \mathrm{m}$. A mixture of glass with the grossular composition and nano-crystalline grossular embryos was found at grain boundaries (d); scale bar, $100 \mathrm{~nm}$. The circles labelled with ED (electron diffraction) indicate the selected areas (by apertures) from which ED images were taken (shown as an inlet of $\mathbf{c}, \mathbf{d}$ ). The latter ED taken from the region labelled GL shows a diffuse halo characteristic of glass (amorphous) material, in addition to diffraction spots from the coexisting nano-crystals.

brown in colour (Fig. 1e, inlet). All of these samples synthesized at temperatures $1,200-1,600{ }^{\circ} \mathrm{C}$ were identified as pure grossular by X-ray diffraction measurements, and were found free of residual pores by TEM observations (Fig. 2a,b) and by density measurements using the Archimedes method (Methods).

TEM image shows the devitrified grossular sample obtained at $1,200^{\circ} \mathrm{C}$ is composed of relatively large grains of grossular up to a few micrometres, having many dislocations and inter-grain crack openings (Fig. 2c). A small amount of remnant glass was also observed along the grain boundaries (Fig. 2d). The large grain size at such a relatively low temperature is attributed to the slow nucleation of garnet in homogeneous glass just above the glass transition temperature ${ }^{15}$ of around $1,150{ }^{\circ} \mathrm{C}$ at this pressure, followed by crystal growth. Nano-polycrystalline grossular with average grain sizes $<100 \mathrm{~nm}$ was found to form at higher temperatures of $1,300-1,500^{\circ} \mathrm{C}$ at $15 \mathrm{GPa}$ (Fig. $1 \mathrm{~b}-\mathrm{d}$ and Supplementary Table 1). This is probably due to the fast nucleation above some threshold temperature between 1,200 and $1,300^{\circ} \mathrm{C}$, which resulted in the instantaneous formation of a large number of garnet crystallites, followed by slow grain growth because of the dry and ultrahigh pressure conditions. In contrast, significant grain growth of up to $\sim 200 \mathrm{~nm}$ was noted for the sample synthesized at a further high temperature of $1,600^{\circ} \mathrm{C}$ (Fig. 1e).

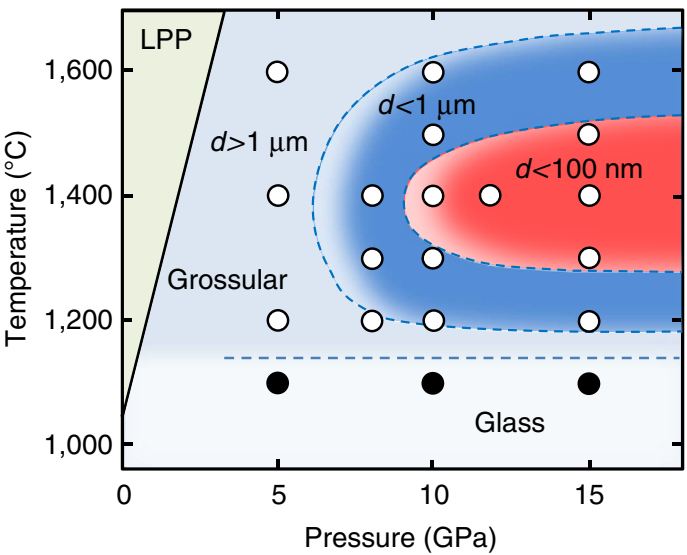

Figure 3 | Pressure and temperature conditions for the synthesis of grossular. Polycrystalline grossular with grain sizes $<1 \mu \mathrm{m}$ is shown in the blue region. Highly transparent nano-polycrystalline garnet was obtained only in the red region at around $1,400^{\circ} \mathrm{C}$ and at pressures at and above $10 \mathrm{GPa}$, while the samples remained glass at $1,100^{\circ} \mathrm{C}$. Note that these results on the grain size may change with the heating time, and the dotted boundaries are applicable to the runs with $2 \mathrm{~h}$ heating at the given pressures and temperatures. LPP, low-pressure phases (anorthite, gehlenite and wollastonite) of grossular ${ }^{38}$

Similar temperature dependency in grain size of grossular was observed at $10 \mathrm{GPa}$ (and at $12 \mathrm{GPa}$ ); nano-polycrystalline garnets formed only at the modest temperatures of $1,400^{\circ} \mathrm{C}$, while those synthesized at $1,200-1,300$ and $1,500-1,600{ }^{\circ} \mathrm{C}$ had larger grains of $150-200 \mathrm{~nm}$. In contrast, the average grain sizes of grossular synthesized at $8 \mathrm{GPa}$ and at $1,200-1,400^{\circ} \mathrm{C}$ were substantially larger than $100 \mathrm{~nm}$, and those synthesized at $5 \mathrm{GPa}$ were even much larger; $33 \pm 13 \mu \mathrm{m}$ at $1,200^{\circ} \mathrm{C} ; 5 \pm 2 \mu \mathrm{m}$ at $1,400^{\circ} \mathrm{C}$; and $7 \pm 3 \mu \mathrm{m}$ at $1,600^{\circ} \mathrm{C}$ (Supplementary Table 1 ). The latter results at the lowest pressure may be due to the smaller nucleation rates near the phase boundary between grossular and the low pressure phases, combined with the faster atomic diffusions at such a relatively low pressure, causing substantial crystal growth in the glass followed by grain growth.

Figure 3 summarizes the pressure and temperature conditions, where grossular crystallizes in various grain sizes from the glass starting material. To obtain nano-polycrystalline garnet, a fast nucleation of garnet without subsequent grain growth is required, which can only be achieved under limited conditions of pressures at and above $\sim 10 \mathrm{GPa}$ and temperatures around $1,400^{\circ} \mathrm{C}$ for grossular. Excluding absorbed water during the ultrahighpressure synthesis is also important, as the presence of even a trace amount of water can yield significantly faster atomic diffusions ${ }^{16}$, causing rapid grain growth. The presence of water may also result in poor grain boundary adhesion and the formation of inter-grain defective regions, which should be avoided in making transparent ceramics. For this purpose, using bulk glass sample, rather than powdered glass, is essentially important to minimize the surface area of the starting sample. Indeed, our attempts to make nano-polycrystalline garnet using powdered glass starting materials failed, and the garnets synthesized under similar pressure and temperature conditions were made of crystals with average grain sizes always $>1 \mu \mathrm{m}$, in spite of careful treatments of the sample and furnace assembly to exclude absorbed water ${ }^{17}$.

Hardness versus grain size. Figure 4 shows Knoop hardness (Hk) of the polycrystalline grossular samples synthesized in the present study as a function of grain size $(d)$. It is clearly seen that the hardness increases by $\sim 30 \%$ with reducing grain size, from 


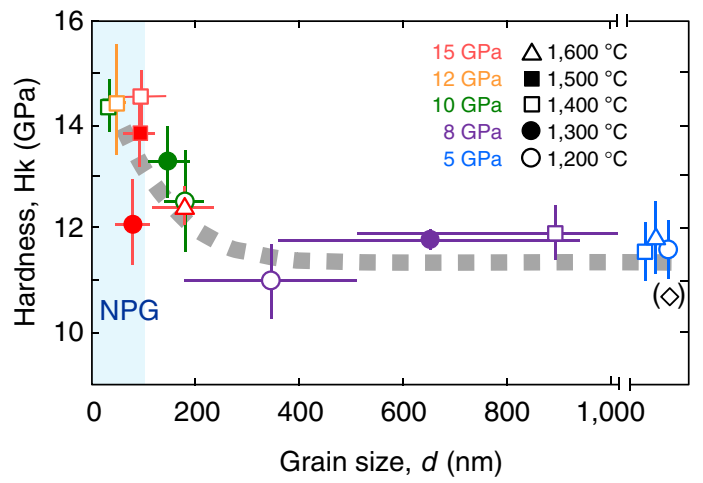

Figure 4 | Knoop hardness versus grain size of the polycrystalline

grossular. The Knoop hardness $(\mathrm{Hk})$ increases with reducing grain size $(d)$ particularly those below $200 \mathrm{~nm}$, suggesting the Hall-Petch effect is applicable to nano-polycrystalline grossular, while no obvious relations of the hardness with either pressure or temperature are noted. Pressures are shown in different colours, while temperatures are shown by different symbols, as indicated in the figure. Open black diamond symbol in a parenthesis represents the hardness of a single crystal of natural grossular with a small ( $<1 \mathrm{wt} \%$ ) amount of $\mathrm{FeO}$ and $\mathrm{MnO}$ (Methods). The hardness data of the samples with $d>1,000 \mathrm{~nm}$ do not correspond to the scale of the horizontal axis, but are plotted in the order of the grain size. The shaded area indicated by NPG (nano-polycrystalline garnet) corresponds to the nano-crystalline region. The measured values of hardness and grain size are listed in Supplementary Table 1, with s.d.'s shown by error bars in this figure.

$\mathrm{Hk}=11.3 \pm 0.5 \mathrm{GPa}$ with $d>200 \mathrm{~nm}$ to $\sim 14.5 \mathrm{GPa}$ at $d=30-50 \mathrm{~nm}$, showing that the Hall-Petch effect ${ }^{18-20}$ known for metals is also applied to some ceramics in the nano-crystalline regime. This is consistent with the recent results on polycrystalline $\mathrm{MgAl}_{2} \mathrm{O}_{4}$ spinel ${ }^{11}$ that concluded the Hall-Petch effect is valid down to the grain size of $30 \mathrm{~nm}$, although there is controversy on the applicable grain size for this effect in ceramics $^{21}$. The latter result on $\mathrm{MgO}$ periclase may be due to insufficient sintering of nano-crystals, and our results on pore-free samples clearly demonstrate the Hall-Petch effect is applied to the nano-ceramics.

Optical transmittance. Figure 5 shows the transmittance of ultraviolet to visible light through the polycrystalline grossular samples with a thickness of $1.0 \mathrm{~mm}$, synthesized at $15 \mathrm{GPa}$ and at different temperatures. The theoretical limit (86.7\%) of the transmittance of visible light predicted from the refractive index of single-crystal grossular $(n=1.734$; ref. 22$)$ is also shown as a reference. The transmittances of the transparent samples synthesized at $1,300,1,400$ and $1,500^{\circ} \mathrm{C}$ are very close to that of the theoretical limit in the visible light range between about 400 and $800 \mathrm{~nm}$ in wavelength. The gradual decrease of the transmittance for wavelengths shorter than $\sim 400 \mathrm{~nm}$ and the sharp decrease below $\sim 300 \mathrm{~nm}$ would be attributed to a combination of the scattering caused by trace amounts of inter-grain defective regions with similar dimensions to the grain sizes $(30-50 \mathrm{~nm})$ presumably formed on the release of pressure and the absorption due to the electronic bandgap of grossular $(5.22 \mathrm{eV}=238 \mathrm{~nm}$; ref. 23). In contrast, the optical transmittance of the dark and brown transparent sample synthesized at $1,600^{\circ} \mathrm{C}$ is substantially lower than the theoretical limit in this wavelength range, which is probably caused by the inter-grain defective regions equivalent to the grain sizes (around 100-200 nm) formed on the pressure release, which should significantly scatter the lights in the visible light range ${ }^{9,10}$. On the other hand, the very low transparency of the sample

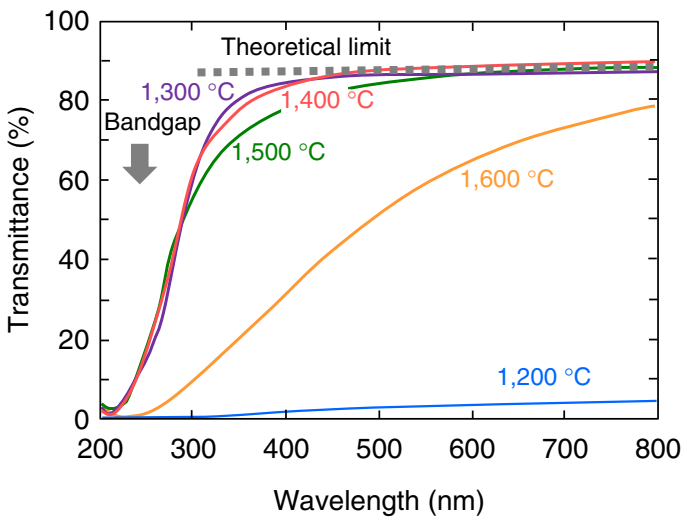

Figure 5 | Transparency of polycrystalline grossular synthesized at

$15 \mathrm{GPa}$. Transmittance of light through the polycrystalline grossular samples with a thickness of $1.0 \mathrm{~mm}$, synthesized at $15 \mathrm{GPa}$ and at $1,200-1,600^{\circ} \mathrm{C}$

(Fig. 1). Dotted line shows the theoretical limit (86.7\%) of the

transmittance calculated from the refractive index of single-crystal grossular. The predicted bandgap $(5.22 \mathrm{eV}=238 \mathrm{~nm}$ in wavelength) of grossular is indicated by the arrow.

crystallized at the lowest temperature $\left(1,200^{\circ} \mathrm{C}\right)$ at $15 \mathrm{GPa}$ is attributed to the scattering of light by a small amount of remnant glass and the openings along the grain boundaries due to incomplete sintering (Fig. 2c,d).

\section{Discussion}

The present direct conversion method at ultrahigh pressure and high temperature using the bulk glass sample first succeeded in producing pore-free nano-crystalline ceramics with the optical transparency comparable to that of the corresponding single crystal. Although highly transparent ceramics have been developed $^{24}$ and successfully applied to some lasers and optical devices ${ }^{25}$, those with single-phase crystals in the nano-crystalline regime have never been produced by either sintering techniques ${ }^{3-7,24}$ or crystallization from glass or amorphous phases $8,26,27$ under the ambient pressure and at relatively low pressures. On the other hand, the transparent nano-ceramics produced by these techniques have substantially low transparency relative to the single crystals in the visible light region ${ }^{11,27}$ mainly due to the presence of a number of residual pores and/or defective regions along grain boundaries. To remove these scattering sources, higher-temperature or longer-duration heating is required, which inevitably leads to grain growth at the low pressures and fails to produce nano-crystalline ceramics. In contrast, our ultrahigh-pressure conversion technique helps strengthening of inter-grain adhesion and also suppresses grain growth due to slower atomic diffusions even at high temperatures, leading to the ceramics with both supertransparency and nano-crystalline nature that have never been achieved in earlier studies.

We confirmed the present ultrahigh-pressure conversion technique can be applied to other silicate garnets with different chemical compositions in producing similarly transparent polycrystalline samples (Fig. 6), which suggests highly transparent nano-crystalline ceramics may be produced wherever bulk glass starting materials are available. As the transparency of sintered polycrystalline materials is predicted to increase in the nanocrystalline regime even for those with optically anisotropic symmetry 9,10 , the present technique using ultrahigh pressure and bulk glass starting material under completely dry conditions should open the door to making novel transparent nano-crystalline ceramics with superior mechanical strength. Moreover, unlike conventional sintering techniques, the present 


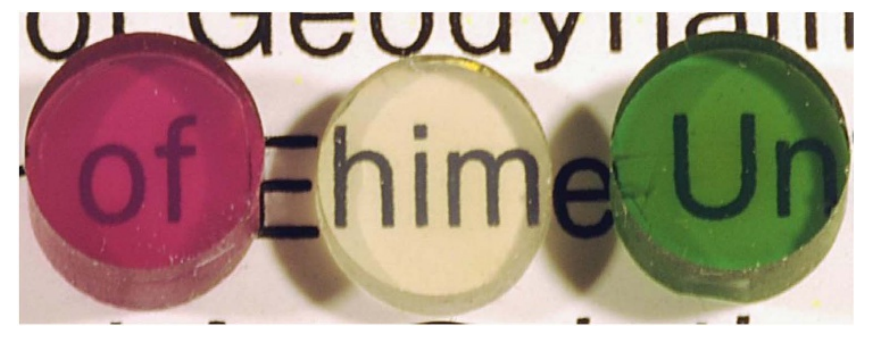

Figure 6 | Transparent nano-polycrystalline garnets with various chemical compositions. Some examples of high-quality polycrystalline garnet synthesized at $15 \mathrm{GPa}$ and at $1,400^{\circ} \mathrm{C}$, with a diameter of $\sim 4 \mathrm{~mm}$ and thickness of $\sim 2 \mathrm{~mm}$; grossular with $2 \mathrm{~mol} \% \mathrm{Ca}_{3} \mathrm{Cr}_{2} \mathrm{Si}_{3} \mathrm{O}_{12}$ uvarovite (green), pure grossular (colourless) and $\mathrm{Mg}_{3} \mathrm{Al}_{2} \mathrm{Si}_{3} \mathrm{O}_{12}$ pyrope with $5 \mathrm{~mol} \%$ knorringite $\mathrm{Mg}_{3} \mathrm{Cr}_{2} \mathrm{Si}_{3} \mathrm{O}_{12}$ (purple).

method does not require the preparation of nano-crystalline powders, which should result in the novel transparent ceramics made of materials with a wide range of chemical compositions.

The present method also has great advantage in making transparent ceramics with high-pressure phases, which generally have higher values in density, elastic stiffness, hardness, refractive index and so on relative to those of the lower pressure phases but have been available mostly as powders or poorly sintered bodies with grain sizes far larger than $100 \mathrm{~nm}$. Sintering of such highpressure phases is difficult under the ambient pressure or at pressures lower than their stability limits, as they transform back to low-pressure phases or amorphous phases. Thus, transparent ceramics of high-pressure phases cannot in principle be produced using conventional methods at relatively low pressures. The present ultrahigh-pressure conversion technique is not only useful in making super-transparent ceramics with materials formed at the ambient pressure but also expands such ceramics to high-pressure phases with more densely packed crystal structures. In fact, all of the garnet specimens in our study are unstable at the ambient pressure at high temperatures ( $\geq \sim 1,000^{\circ} \mathrm{C}$ ), and cannot be produced by any conventional sintering techniques at the low pressures.

Precise measurements of sound velocities of high-pressure minerals are important to constrain the composition and constitution of the Earth's deep interior via comparisons with seismologically derived velocity models ${ }^{28}$. Transparent samples are needed for the measurements of sound velocities by Brillouin scattering technique ${ }^{29}$, and its application has mostly been limited to single crystals due to the unavailability of highly transparent polycrystalline bulk samples of high-pressure minerals suitable for such measurements, except for very thin samples $^{30}$. Techniques for ultrasonic measurements in $\mathrm{GHz}$ regime have also been developed for sound velocity measurements of tiny samples ${ }^{31}$ such as synthesized at high pressure and temperature. Its application to polycrystalline samples, however, has not been made except for a recent study on NPD ${ }^{32}$, as it requires well-sintered specimens with grain sizes $<\sim 1 \mu \mathrm{m}$ to avoid the effect of grain boundary scattering of the ultrasonic waves in the $\mathrm{GHz}$ range.

The ultrahigh-pressure conversion technique provides specimens ideal for these sound velocity measurements, and thereby greatly contributes to the mineralogical studies of the Earth's interior. Moreover, this technique provides super-transparent nano-crystalline ceramics with enhanced hardness, which are important for optical devices, including windows and lenses used in severe environments under high pressure, temperature and erosive conditions. Ease of doping minor elements in glass starting material for the ultrahighpressure conversion is also potentially important in making super-transparent ceramics for lasers, scintillators and other photonic devices, as well as for gem stones. Furthermore, applicability of the present technique to high-pressure phases with various crystal structures and advanced physical properties would lead to completely new and unique functional ceramics for scientific and industrial applications.

\section{Methods}

High-pressure experiments. We used bulk glass starting material with a composition of $\mathrm{Ca}_{3} \mathrm{Al}_{2} \mathrm{Si}_{3} \mathrm{O}_{12}$, which was made by de-carbonation and subsequent melting of a mixture of $\mathrm{CaCO}_{3}, \mathrm{Al}_{2} \mathrm{O}_{3}$ and $\mathrm{SiO}_{2}$ in a furnace, followed by quenching under air to suppress development of cracks. The bulk glass, without any visible cracks and bubbles, was cored with an ultrasonic machining device to make a rod with a diameter of $4.5 \mathrm{~mm}$ and a length of $3 \mathrm{~mm}$. The glass rod starting material was wrapped with a thin foil (thickness of $50 \mu \mathrm{m}$ ) of pure iron, which reacts with a trace amount of water from air that could be present on the surface of the rod samples according to the reaction $\mathrm{Fe}+\mathrm{H}_{2} \mathrm{O} \rightarrow \mathrm{FeO}+\mathrm{FeH}_{x}$ under the present pressure and temperature conditions ${ }^{33}$. The sample was further enclosed in a gold capsule and inserted into the cell assembly shown in Supplementary Fig. 1, which was dried at $150^{\circ} \mathrm{C}$ in an oven before being assembled. All the procedures of assembling $\mathrm{Au}$ capsule, $\mathrm{MgO}$ electric and $\mathrm{LaCrO}_{3}$ thermal insulators, Pt heater and $\mathrm{MgO}-\mathrm{CoO}$ pressure medium were made on a hot plate at $150^{\circ} \mathrm{C}$. The cell assembly was kept in the oven until commencement of the ultrahigh-pressure synthesis runs

The cell suffered pressures of $5-15 \mathrm{GPa}$ and temperatures of $1,100-1,600^{\circ} \mathrm{C}$ for $2 \mathrm{~h}$ in multianvil apparatus. Temperature was then decreased to $800^{\circ} \mathrm{C}$, and pressure was slowly released while the temperature was kept constant to reduce deviatoric stress in the sample so that development of cracks was minimized on decompression. The recovered samples at the ambient pressure were analysed using various techniques.

The ultrahigh-pressure synthesis of grossular was made with a Kawai-type 6-8 multianvil apparatus ${ }^{34}$ operated in a 3,000 ton press (ORANGE-3000) at the Geodynamics Research Center. To secure the larger sample volumes, we did not insert thermocouple wires to measure temperature in the high-pressure cell, and instead the temperature was evaluated by the predetermined electric power-temperature relations at 5,10 and $15 \mathrm{GPa}$. Because of some difference in the temperature generation efficiency due to different deformation behaviours of Pt foil heater under pressure from run to run, temperature uncertainties of $\sim 5 \%$ of the nominal values are unavoidable. Pressure was estimated based on the phase transitions in some reference materials, and may also suffer uncertainties of $\sim 5 \%$.

The bulk glass samples of garnet stoichiometry with other compositions, such as $\mathrm{Mg}_{3} \mathrm{Al}_{2} \mathrm{Si}_{3} \mathrm{O}_{12}$ (pyrope) and solid solutions between $\mathrm{Ca}_{3} \mathrm{Al}_{2} \mathrm{Si}_{3} \mathrm{O}_{12}$ and $\mathrm{Ca}_{3} \mathrm{Cr}_{2} \mathrm{Si}_{3} \mathrm{O}_{12}$ (uvarovite) and those between $\mathrm{Mg}_{3} \mathrm{Al}_{2} \mathrm{Si}_{3} \mathrm{O}_{12}$ and $\mathrm{Mg}_{3} \mathrm{Cr}_{2} \mathrm{Si}_{3} \mathrm{O}_{12}$ (knorringite) were also used as the starting materials for comparison. The bulk glass starting materials were prepared using the same procedures as those used in making the bulk glass with the grossular composition. For the synthesis of larger and crack-free samples of garnets with the compositions shown in Fig. 6, we used a multianvil apparatus operated in a 6,000 ton press (BOTCHAN-6000) ${ }^{13}$ at the Geodynamics Research Center. The design of the cell assembly adopted for these runs was virtually the same as shown in Supplementary Fig. 1 (except for the dimensions), but we used a softer $\mathrm{NaCl}$, instead of $\mathrm{MgO}$, as an electric insulator for the metal capsule to reduce the influence of deviatoric stress in the sample on the release of pressure. The grain sizes of the synthesized pyrope-rich garnets at $15 \mathrm{GPa}$ and $1,400^{\circ} \mathrm{C}$ were somewhat larger than those of grossular after the high-pressure and high-temperature synthesis for $2 \mathrm{~h}$, but these may be reduced to $<100 \mathrm{~nm}$ by adopting shorter run durations.

Phase identification and chemical analysis. The recovered samples were first examined by an X-ray diffractometer (Rigaku, Rapid II) operated at $40 \mathrm{kV}$ and $30 \mathrm{~mA}$ for phase identification. A Cu-K $\alpha$ radiation (collimated to $\sim 100 \mu \mathrm{m}$ ) was used for the measurements and the diffraction patterns were recorded on an imaging plate. The $2 \theta$-intensity profiles were obtained by integrating the pixel intensity over definite angular sectors. The samples below $1,200^{\circ} \mathrm{C}$ remained glass with the characteristic halo background in the X-ray diffraction profiles, but those at and above $1,200^{\circ} \mathrm{C}$ at all pressures were identified as pure garnet based on identification of all the diffraction peaks.

Field emission-SEM (scanning electron microscope; JEOL, JSM-7000F) with an energy-dispersive X-ray spectrometer (Oxford, X-Max 20) was used for microstructure and chemical composition analyses. Before analyses, the mirror-polished samples were coated with carbon of $\sim 25 \mathrm{~nm}$ thick to prevent charging. Chemical quantification analysis was conducted at a beam current of $1 \mathrm{nA}$ with an accelerating voltage of $20 \mathrm{kV}$, leading to the results that show the glass starting material and the synthesized grossular have identical bulk compositions of $\mathrm{Ca}_{3} \mathrm{Al}_{2} \mathrm{Si}_{3} \mathrm{O}_{12}$ within the uncertainties of the measurements $(<0.5 \%)$.

Microstructure observation. The grain boundaries were not clearly observed on the polished surface in most of the polycrystalline garnet samples using the field emission-SEM, except for the samples synthesized at $5 \mathrm{GPa}$ and that at $1,200^{\circ} \mathrm{C}$, at $15 \mathrm{GPa}$. For grain size measurements of some samples composed of 
micrometre-size grains, fracture surfaces were prepared and coated with osmium of $\sim 5 \mathrm{~nm}$ thick to minimize charging effect.

Microtexture analysis of the samples was also performed by using a TEM (JEOL, JEM-2100 F) operated at $200 \mathrm{kV}$. Thin cross-section foils of about $10 \times 5 \mu \mathrm{m}$ with a thickness of $0.1-0.2 \mu \mathrm{m}$ were prepared by using a focus-ion beam (JEOL, JEM-9310FIB) system. Any residual pores in the transparent samples were not detected by TEM observations, as shown by the high-resolution images of such samples (Fig. 2a,b). This is reasonable for the samples synthesized at such ultrahigh pressures and high temperatures in the present study as the pores can be totally collapsed in the sintered samples at pressures above $\sim 2$ GPa (ref. 35), in addition to the use of bulk glass starting material without any visible cracks and bubbles. The porosities of some of the transparent samples determined by the Archimedes method were within the uncertainties of the measurements $(\sim 0.5 \%)$ and are probably far less than these uncertainties and difficult to be evaluated by this method, as suggested in the case for NPD ${ }^{32}$. For the opaque sample obtained at $1,200^{\circ} \mathrm{C}$ at $15 \mathrm{GPa}$ (Fig. 1a), the presence of small patches of remnant glass was confirmed along some grain boundaries (Fig. 2c,d).

Grain size distribution. Grain sizes of the polycrystalline samples composed mainly of grains of $<200 \mathrm{~nm}$ were determined by direct measurement of 100 grains that appear black (that is, satisfying the Bragg condition) in the TEM images taken with an objective lens aperture. This procedure gave realistic size distributions of randomly referred grains (Fig. 1 and Supplementary Fig. 2). Grain sizes of the samples composed of larger $(>200 \mathrm{~nm})$ grains were measured by the intercept method for 100 grains using SEM (for grain sizes larger than 1,000 nm) and TEM images. The distributions of grain size for the samples synthesized at $1,200-1,600{ }^{\circ} \mathrm{C}$ at $15 \mathrm{GPa}$ (Fig. 1) are shown in Supplementary Fig. 2 and Supplementary Table 1 .

Water content. Micro Fourier transform infrared (FT-IR; PerkinElmer, Spectrum One) spectroscopic observation was made on a polycrystalline garnet sample synthesized from a glass powder to evaluate its water content after polishing to a thin section, but no observable absorption bands relevant to the hydroxyl were detected, suggesting that the sample was almost completely dry within the detection limit (less than a few p.p.m.). This sample, synthesized at $15 \mathrm{GPa}$ and at $1,400^{\circ} \mathrm{C}$, has an average grain size of $\sim 2 \mu \mathrm{m}$ and should contain a larger amount of absorbed water as compared with the present samples synthesized from bulk glass starting material, indicating that quantitative evaluation of the water content cannot be made by the FT-IR measurement. As the bulk glass was obtained by quenching under air, instead of using the conventional procedure of dropping the sample into water, and very careful treatment in excluding absorbed water was made throughout the experiments, we believe virtually no water is present in the present polycrystalline garnet samples.

Hardness. The hardness of the recovered samples was measured by a durometer with a Knoop indenter (Shimazu, HMV-G), which was pushed on the polished surface of the sample with a load of $0.98 \mathrm{~N}$ for $15 \mathrm{~s}$. A standard metal block with hardness of 9.0 GPa (in Vickers scale) was used as the reference, yielding the Knoop hardness of $8.8 \pm 0.1 \mathrm{GPa}$ in the present measurement, which is slightly lower but marginally consistent with the recommended value. Knoop hardness of a single crystal of natural grossular with small amounts of $\mathrm{Fe}(\mathrm{FeO}=\sim 0.6 \mathrm{wt} \%)$ and $\mathrm{Mn}(\mathrm{MnO}=\sim 0.4 \mathrm{wt} \%)$ was measured by the same method, resulting in the hardness of $10.7 \pm 0.3 \mathrm{GPa}$, which is also slightly lower than that measured in Vickers hardness of $10.9 \pm 0.4 \mathrm{GPa}$. The lower values of Knoop hardness relative to those of Vickers hardness are consistent with the general trend for hard ceramics ${ }^{36}$, and we used the Knoop hardness throughout the present measurements without any corrections based on the measurement on the standard metal block. The measurement on the synthesized grossular samples was repeated on 10-15 points for each sample, and the results were averaged and shown in Supplementary Table 1 with the s.d.'s. It should be noted that the hardness of a single crystal may vary depending on the crystal plane and direction ${ }^{37}$. Nevertheless, the hardness of the single-crystal grossular is consistent with those of the polycrystalline samples with grain sizes far larger than $1 \mu \mathrm{m}$ within the uncertainties (Fig. 4).

Optical transmittance. Transmittance of lights in an ultraviolet to visible range (200-800 nm) was measured using a spectrophotometer (JASCO, V-670) equipped with an integral sphere assembly to minimize the effect of light scattering on the mirror-polished grossular samples with a thickness of $1.0 \mathrm{~mm}$. The data for 50 measurements were stacked to reduce the noise level. The roughness of the sample surface and its inclination to the incident light may affect the transmittance, which is estimated to be of the order of $2-3 \%$ in the present measurements according to the reproducibility of the measured transmittance.

Data availability. No data sets were generated or analysed during the current study, but the original data in this article and some of the original samples are available from the corresponding author on reasonable request.

\section{References}

1. Wang, S. F. et al. Transparent ceramics: processing, materials and applications. Prog. Solid State Chem. 41, 20-54 (2013).

2. Fahlman, B. D. Material Chemistry (Springer, 2007).

3. Nishiyama, N. et al. Transparent nanocrystalline bulk alumina obtained at $7.7 \mathrm{GPa}$ and $800^{\circ} \mathrm{C}$. Scr. Mater. 69, 632-635 (2013).

4. Sokol, M., Kalabukhov, S., Dariel, M. P. \& Frage, N. High-pressure spark plasma sintering (SPS) of transparent polycrystalline magnesium aluminate spinel (PMAS). J. Eur. Ceram. Soc. 34, 4305-4310 (2014).

5. Morita, K., Kim, B.-N., Yoshida, H., Hiraga, K. \& Sakka, Y. Spectroscopic study of discoloration of transparent $\mathrm{MgAl}_{2} \mathrm{O}_{4}$ spinel fabricated by spark-plasmasintering (SPS) processing. Acta Mater. 84, 9-19 (2015).

6. Ehre, D., Gutmanas, E. Y. \& Chaim, R. Densification of nanocrystalline MgO ceramics by hot-pressing. J. Eur. Ceram. Soc. 25, 3579-3585 (2005).

7. Krell, A. \& Bales, A. Grain size-dependent hardness of transparent magnesium aluminate spinel. Int. J. Appl. Ceram. Technol. 8, 1108-1114 (2011).

8. Alahraché, S. et al. Perfectly transparent $\mathrm{Sr}_{3} \mathrm{Al}_{2} \mathrm{O}_{6}$ polycrystalline ceramics elaborated from glass crystallization. Chem. Mater. 25, 4017-4024 (2013).

9. Apetz, R. \& Bruggen, M. P. B. Transparent alumina: a light-scattering model. J. Am. Ceram. Soc. 86, 480-486 (2003).

10. Suárez, M., Fernández, A., Torrecillas, R. \& Menéndez, J. L. in Sintering of Ceramics-New Emerging Techniques (ed. Lakshmanan, A.) 527-552 (InTech, 2012).

11. Wollmershauser, J. A. et al. An extended hardness limit in bulk nanoceramics. Acta Mater. 69, 9-16 (2014).

12. Irifune, T., Kurio, A., Sakamoto, S., Inoue, T. \& Sumiya, H. Ultrahard polycrystalline diamond from graphite. Nature 421, 599-600 (2003).

13. Irifune, T., Isobe, F. \& Shinmei, T. A novel large-volume Kawai-type apparatus and its application to the synthesis of sintered bodies of nano-polycrystalline diamond. Phys. Earth Planet. Inter. 228, 255-261 (2014).

14. Nishiyama, N. et al. Synthesis of nanocrystalline bulk SiO2 stishovite with very high toughness. Scripta Mater. 67, 955-958 (2012).

15. Holand, W. \& Beall, G. H. Glass-Ceramic Technology 2nd edn (Wiley, 2012). 16. Karato, S. Deformation of Earth Materials (Cambridge Univ. Press, 2008).

17. Arimoto, T., Greaux, S., Irifune, T., Zhou, C. \& Higo, Y. Sound velocities of $\mathrm{Fe}_{3} \mathrm{Al}_{2} \mathrm{Si}_{3} \mathrm{O}_{12}$ almandine up to $19 \mathrm{Gpa}$ and $1700 \mathrm{~K}$. Phys. Earth Planet. Inter. 245, 1-8 (2015).

18. Hall, E. O. The deformation and ageing of mild steel: III discussion of results. Proc. Phys. Soc. B 64, 747 (1951).

19. Petch, N. J. The cleavage strength of polycrystals. J. Iron Steel Inst. 174, 25-28 (1953).

20. Hall, E. O. Variation of hardness of metals with grain size. Nature 173, 948-949 (1954).

21. Ehre, D. \& Chaim, R. D. Abnormal Hall-Petch behavior in nanocrystalline MgO ceramic. J. Mater. Sci. 43, 6139-6143 (2008).

22. Weber, M. J. Handbook of Optical Materials (CRC Press, Taylor \& Francis, 2002).

23. Cano, N. F., Ayata, W. E. F. \& Watanabe, S. Electronic and optical properties of grossular garnet $\left(\mathrm{Ca}_{3} \mathrm{Al}_{2} \mathrm{Si}_{3} \mathrm{O}_{12}\right)$ : an ab initio study. Opt. Mater. 32, 566-569 (2010).

24. Ikesue, A., Kinoshita, T., Kamata, K. \& Yoshida, K. Fabrication and optical properties of high-performance polycrystalline Nd:YAG ceramics for solid-state lasers. J. Am. Ceram. Soc. 78, 1033-1040 (1995).

25. Ikesue, A. \& Aung, Y. L. Ceramic laser material. Nat. Photon. 2, 721-727 (2008).

26. Bonnell, A., Tien, T. Y. \& Ruhle, M. Controlled crystallization of the amorphous phase in silicon nitride ceramics. J. Am. Ceram. Soc. 70, 460-465 (1987).

27. Rosenflanz, A., Frey, M., Endres, B., Anderson, T., Richards, E. \& Schardt, C. Bulk glasses and ultrahard nanoceramics based on alumina and rare-earth oxides. Nature 430, 761-764 (2004).

28. Irifune, T. et al. Sound velocities of majorite garnet and the composition of the mantle transition region. Nature 451, 814-817 (2008).

29. Speziale, S., Marquardt, H. \& Duffy, T. S. Brillouin scattering and its application in geosciences. Rev. Mineral. Geochem. 78, 543-603 (2014).

30. Murakami, M., Ohishi, Y., Hirao, N. \& Hirose, K. A perovskitic lower mantle inferred from high-pressure, high-temperature sound velocity data. Nature 485, 90-94 (2012).

31. Spetzler, H. A., Chen, G., Whitehead, S. \& Getting, I. C. A new ultrasonic interferometer for the determination of equation of state parameters of sub-millimeter single crystals. Pure Appl. Geophys. 141, 341-377 (1993)

32. Chang, Y. Y., Jacobsen, S. D., Kimura, M., Irifune, T. \& Ohno, I. Elastic properties of transparent nano-polycrystalline diamond measured by GHz-ultrasonic interferometry and resonant sphere methods. Phys. Earth Planet. Inter. 228, 47-55 (2014).

33. Ohtani, E., Hirao, N., Kondo, T., Ito, M. \& Kikegawa, T. Iron-water reaction at high pressure and temperature, and hydrogen transport into the core. Phys. Chem. Minerals 78, 77-82 (2005) 
34. Kawai, N. \& Endo, S. The generation of ultrahigh pressure by a split sphere apparatus. Rev. Sci. Instrum. 41, 1178-1181 (1970).

35. Rigden, S. M., Jackson, I., Niesler, H. \& Ringwood, A. E. Pressure dependence of the elastic wave velocities for $\mathrm{Mg}_{2} \mathrm{GeO}_{4}$ spinel up to $3 \mathrm{GPa}$. Geophys. Res. Lett. 6, 605-608 (1988).

36. Chicot, D. et al. Comparison of instrumented Knoop and Vickers hardness measurements on various soft materials and hard ceramics. J. Eur. Ceram. Soc. 27, 1905-1911 (2007).

37. Sumiya, H. \& Irifune, T. Indentation hardness of nano-polycrystalline diamond prepared from graphite by direct conversion. Diamond Rel. Mater. 13, 1771-1776 (2004).

38. Perkins, D. III, Essene, E. J., Westrum, E. F. Jr \& Wall, V. J. Application of new thermodynamic data to grossular phase relations. Contrib. Mineral. Petrol. 64, 137-147 (1977).

\section{Acknowledgements}

This work is funded by JSPS Grant-in-Aid for Scientific Research (No. 25220712 and No.15H05829) to T. I., who thanks to T. Kawazoe and Y. Nishihara for helping in FT-IR analysis and ultrasonic coring of the starting glass, respectively. Thanks are also due to A. Ikesue, N. Nishiyama, K. Fujino, M. Nishi, T. Ohuchi and T. Inoue for discussion, to

M. Matsushita for instruction in measuring Knoop hardness, and to D. Furuta and

K. Takahashi for some additional runs on pyrope and grossular compositions.

\section{Author contributions}

T.I. directed the whole research project and wrote the manuscript; K.K. made most of the high-pressure experiments and analyses of the run products, assisted by T.A., T.K. and
T.S.; synthesis of the polycrystalline garnets with the compositions other than grossular were made by T.A., T.K. and T.S.; TEM analyses of the run products were conducted by H.O.

\section{Additional information}

Supplementary Information accompanies this paper at http://www.nature.com/ naturecommunications

Competing financial interests: The authors declare no competing financial interests.

Reprints and permission information is available online at http://npg.nature.com/ reprintsandpermissions/

How to cite this article: Irifune, T. et al. Pressure-induced nano-crystallization of silicate garnets from glass. Nat. Commun. 7, 13753 doi: 10.1038/ncomms13753 (2016).

Publisher's note: Springer Nature remains neutral with regard to jurisdictional claims in published maps and institutional affiliations.

\section{(c) (i)}

This work is licensed under a Creative Commons Attribution 4.0 International License. The images or other third party material in this article are included in the article's Creative Commons license, unless indicated otherwise in the credit line; if the material is not included under the Creative Commons license, users will need to obtain permission from the license holder to reproduce the material. To view a copy of this license, visit http://creativecommons.org/licenses/by/4.0/

(C) The Author(s) 2016 